
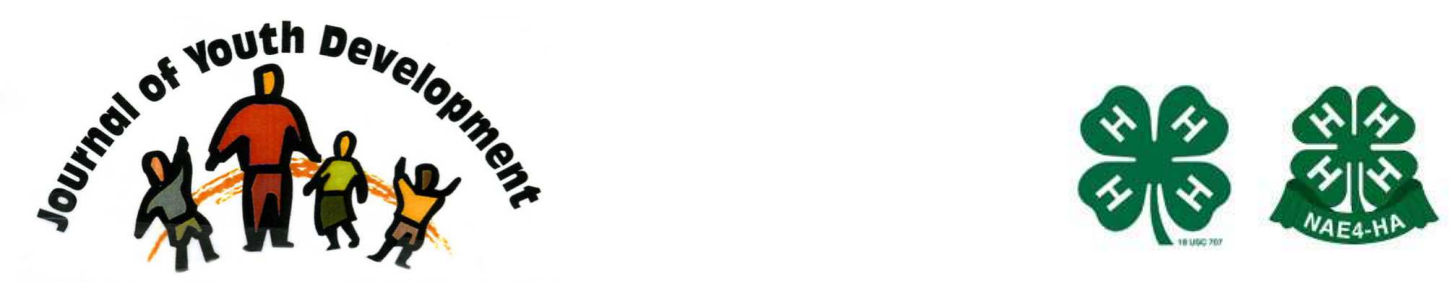

Bridging Research \& Practice

\title{
Skateboard Park Participation: A Means-end Analysis
}

\author{
Marni Goldenberg \\ Recreation, Parks, and Tourism Administration \\ California Polytechnic State University \\ San Luis Obispo, CA \\ mgoldenb@calpoly.edu \\ Wynn Shooter \\ Sport and Outdoor Recreation \\ Monash University \\ Frankston, VIC \\ Australia \\ wynn.shooter@education.monash.edu.au
}




\title{
JOURNAL OF YOUTH DEVELOPMENT \\ bridging research and practice

\section{Skateboard Park Participation: A Means-end Analysis}

\author{
Marni Goldenberg \\ California Polytechnic State University \\ Wynn Shooter \\ Monash University
}

\begin{abstract}
Skateboarding has become a highly visible and popular activity. However, many negative stereotypes remain associated with the activity and its participants (Jones \& Graves, 2000). In contrast to the negative stereotypes, skateboarding seems to provide many individuals, and youth in particular, with an important outlet for physical activity, leisure, and personal development. The purpose of this study was to investigate why skateboarders chose to visit skateboard parks, to identify outcomes of participating in skateboarding at skateboard parks, and to identify the underlying values that guide skateboarders' choice of this specific setting. The conceptual framework for the reported study was provided by a means-end model, which views values as the key force influencing an individual's decision to engage in a particular behavior (Gutman, 1982; Manyiwa \& Crawford, 2002). The results indicate that this sample of skateboarders received a number of important benefits and, despite stereotypical views, may seek positive outcomes through skateboarding at skateboard parks. A socio-ecological model and a positive youth development framework provide a platform for interpreting the results and implications.
\end{abstract}

\section{Introduction}

It is clear that with large corporate sponsorships and televised competitions, skateboarding has emerged from its roots of carving the concrete banks in southern California's schoolyards to a highly visible and popular activity. As the number of skateboarders has increased, many communities have viewed skateboarding as a problem (Dahlgren, 2006; Howell, 2005; Young 2004). Likewise, there are many negative stereotypes associated with the activity itself (e.g., property damage to public fixtures like handrails and ledges) and its participants (e.g., 
delinquency and defiance) (Jones \& Graves, 2000). Rankin (1997) agreed that "many skaters [skateboarders] are viewed as unruly vandals and dangers to themselves and the public" ( $p$. 55). In contrast to the negative stereotypes, skateboarding seems to provide an important outlet for physical activity, leisure, and personal development for many individuals.

For example, researchers have given considerable attention to the problem of inactivity among adolescents and authors have asserted that today's adolescents face increasing challenges to living active lifestyles (Hills, King, \& Armstrong, 2007; Morantz \& Torrey, 2004). Obesity and cardiovascular disease are often associated with inactivity and it is widely accepted that physical activity is an effective way to overcome these and other health related challenges (Ransdell et al., 2004; West \& Shores, 2008). Skateboard parks represent one outlet among other programs and facilities offered by community recreation centers that can address a growing problem of youth inactivity.

Although researchers have produced very little empirical evidence to date, Lemmon and Nowlin (2007) made the case that skateparks provide outlets for experiencing success in a safe and supportive setting. Such thinking is consistent with that of Lee (2003) who suggested that skateparks have the potential to serve as centers of youth development. Likewise, the presence of a skateboard park can increase the number of available leisure choices and provide an important meeting place for individuals who share a common interest (Dahlgren, 2006). According to Shannon and Werner (2008) skateparks, "provided opportunities for youth to gather, relax, and hang out with friends while participating in an activity that was important to them" (p. 52).

While some authors agree that skateboard parks can serve as centers for positive youth development, only recently have researchers attempted to explore specific links between skateboarding at skateboard parks and outcomes related to positive youth development. Shannon and Werner (2008) interviewed 8 users of a newly constructed skateboard park in Canada and concluded that the skateboard park provided important leisure opportunities for those youth. Enhanced leisure opportunities support efforts to enact a positive youth development framework by focusing on the developmental potential of youth instead of focusing on treating their deficits (Bocarro, Greenwood, \& Henderson, 2008). While not all skateboard park users are young adults, many are, and young adults need a variety of leisure options in order to overcome the many health and developmental challenges that they face today.

Like any single component of a comprehensive recreation program, community recreation centers invest in skateboard parks with hopes that participants will receive a variety of benefits. However, any positive outcomes associated with skateboard park use remain understood vaguely at best. There is currently little empirical explanation for how participants might achieve such outcomes through using a skateboard park or why participants might be drawn to utilize these facilities. Therefore, the purpose of this exploratory study was to identify outcomes of skateboarding at community skateboard parks. The study also hoped to gain a preliminary understanding of the process or mechanisms through which visitors achieved those outcomes by investigating why skateboarders choose to visit skateboard parks and by identifying the underlying values that guide their desire to utilize this specific setting. 


\section{Methodology}

The conceptual and analytical framework for this study was provided by a means-end model, which views values as the key force influencing an individual's decision to engage in a particular behavior (Gutman, 1982; Manyiwa \& Crawford, 2002). Initially, the means-end approach to understanding behavior was used to study consumer choice and/or decision-making behavior (Gutman, 1982; Mulvey, Olson, Celsi \& Walker, 1994; Walker \& Olson, 1991). Since then, a number of researchers have used means-end as a technique to study leisure and recreation behavior (Frauman, \& Cunningham, 2001; Goldenberg, Hill, \& Freidt, 2008; Goldenberg, Klenosky, O'Leary, \& Templin, 2000; Goldenberg, McAvoy, \& Klenosky, 2005; McAvoy, Holman, Goldenberg, \& Klenosky, 2006).

The interviewing process of the means-end framework is called laddering, which results in qualitative data (Reynolds \& Gutman, 1988). An interviewer asks a respondent a series of structured, but open-ended questions that gradually progress from concrete attributes to abstract values. The goal of laddering is to determine "why a particular concept is important to the respondent" (Goldenberg et al., 2000, p. 212). For example, the present study asked, "Why do you come to the skateboard park?" The response given by the participant ("to skate with my friends") is then utilized in the next rung of the ladder. To continue this example, the next question in this laddering process might be, "Why is skateboarding with your friends important to you?" This process of continuing to use the participant's response to generate the next "Why is ___ important to you" is repeated until the participant no longer has an answer to give. According to the means-end framework, this line of questioning brings the respondent further along a continuum from concrete, objective responses (the means) to more abstract values that are important to the individual (the ends) (Klenosky, Gengler, \& Mulvey,1993; Reynolds \& Gutman, 1988). This process allows researchers to identify linkages in responses and thereby identify the outcomes that participants believe they receive from engaging in a behavior as well as the underlying values that drive that behavior.

The laddered responses are reviewed by the researchers and "aggregated to identify the major patterns of relationships among the elicited concepts" (Goldenberg et al, 2000, p. 213). The review of the data results in content codes based on informants' responses, similar to the "cutup-and-put-in-folders" approach (Bogdan \& Biklen, 1982), which has been used successfully in prior recreation (Hultsman, 1996) and means-end research (Goldenberg et al., 2000, McAvoy et al., 2006). The coded ladder elements are then entered into LadderMap software program (Gengler \& Reynolds, 1995) to facilitate data analysis. This program produces an implication matrix, which is an asymmetric matrix summarizing the number of times each concept was associated with each of the other concepts in informants' ladders (Klenosky, Frauman, Norman, \& Gengler, 1998). Based on these associations, a hierarchical value map (HVM) is created that provides a graphic summary of the linkages in the data (Gengler et al., 1995).

The HVM has lines and circles that represent the relationships among various attributes, consequences, and values. The thickness of the lines and the size of the circle indicates the number of times that concept or that link was indicated by the respondents. In other words, the HVM depicts the major patterns of relationships among the participant's responses and provides a view of the laddered responses as they progress from concrete objects and behaviors to more abstract values. This progression is often referred to as a means-end chain (Goldenberg et al., 2000). As displayed in the HVM, this chain consists of the three links previously mentioned: attributes, consequences, and values. Attributes are viewed as being relatively concrete and are the characteristics or features of the product, object, or activity in question (Goldenberg et al., 
2005). Consequences are viewed as more abstract and refer to outcomes associated with particular attributes. Consequences refer to desired outcomes, more commonly called benefits, but also to undesirable outcomes, such as costs and perceived risks. Values are highly abstract and summarize desired end-states of being (Goldenberg et al., 2000).

Means-end allows researchers to develop an explanation of mechanisms by identifying relationships between attributes, consequences, and values. For example, Haras, Bunting, and Witt (2005) utilized a means-end approach to examine the process whereby youth achieved outcomes of participation in an intentionally designed ropes course program. They suggested that by linking the physical attributes of a program with immediate outcomes (consequences) and the distal outcomes (values or end states), program designers can consider the complete experience of participants and thereby make informed decisions about program design. Haras and colleagues concluded by suggesting that all types of recreational programs need a thorough, organized, working knowledge of the process that guides outcome-based programming.

\section{Procedure}

Modern skateboard parks are built both indoors and outdoors and offer a variety of terrain features designed specifically for use by skateboarders. Although, private skateboard parks have re-emerged, most are indoor facilities and charge fees in exchange for scheduled access to the facility. The current study was concerned with public skateboard parks as those facilities are believed to serve as outlets for positive youth development. Some communities offer multiple public skateboard parks, while others offer none. Most modern, community skateboard parks offer features that simulate urban artifacts, such as ledges, benches, curb cuts, concrete embankments, and rails. These were the types of skateboard parks included in the present study.

The researchers visited nine community skateboard parks; 4 were in Salt Lake City, Utah and 5 were in the Central Coast region of California. These two locations were chosen primarily out of convenience, but also to explore the possibility of differences among skateboarders within these two regional locations. Upon arriving to the skateboard park, interviewers approached skateboarders casually and asked them if they would be willing to participate in the study by responding to a short interview. Unlike many qualitative techniques, the laddering process allows researchers to access a relatively large sample due to the structure of the laddered questioning technique. Once an interviewer had gained consent, he or she conducted the laddering interview as previously explained. The interviews were conducted between July and September 2006.

The interview responses were analyzed by three researchers who worked together to enter the data and develop the initial content codes. A fourth researcher who was familiar with meansend theory but not familiar with this study coded the data and the coders were in $81.33 \%$ agreement. This level of agreement was similar to that obtained in prior means-end research (Goldenberg et al., 2000; Klenosky et al., 1993). The disagreements were resolved by the original researchers.

Once the content codes were developed, the coded ladder elements were entered into the LadderMap software program. LadderMap software produced an implications matrix which is a chart that shows the connections between the various responses. From an implication matrix, 
an HVM is developed which graphically demonstrates the links between the attributes, consequences, and values.

\section{Results}

Informants for this study were 171 skateboarders who visited skateboard parks in Salt Lake City, UT (49.12\%, n= 84) and the Central Coast of California (50.88\%, $n=87)$. No notable differences were discovered between these two groups. Respondents ranged in age from 10-45 years old, with the majority $(79 \%, \mathrm{n}=135)$ between 10 and 21 years old. The majority were male $(94.7 \%, n=162)$, white $(84.2 \%, n=144)$, and high school or college students $(69 \%$, $\mathrm{n}=118)$.

Within the data, 32 content codes were present that consisted of nine attributes (representing why an individual chose to skateboard at the park), 16 consequences (representing what an individual "got out of" skateboarding at the park), and seven personal values (describing why that consequence was important to the individual). The attributes and their definitions included: bowls, designated area and environment - not crowded, interactions - skate park provides opportunity to interact with others, location, simulate street environment, skating skateboarding, skate park, terrain, and tricks. The 16 consequences were: avoid boredom/ be entertained, camaraderie and social opportunities, creative expression/freedom, excitement, fun (at that moment in time the individual was having a fun time), healthy living, meaning and purpose, mental engagement and development, motivation inspiration encouragement, new opportunities, physical fitness, recognition, relieve stress/escape, safety, skill development, and stay out of trouble. The values included: ambition, fun and enjoyment of life (overall in their life), self betterment, self-esteem, self-reliance, sense of accomplishment, and warm relationships with others.

The following examples demonstrate the qualitative responses and the codes that were assigned to the responses. Once demographic information was obtained the individual was asked to explain what outcomes they obtain from using a skateboard park. One individual stated they "hang out with friends/there is someone to talk to" (attribute = interactions), which lead to "teach you new things/know more" (consequence = mental engagement), which lead to "makes you want to try harder/push harder" (consequence = skill development), which lead to "get better and become professional/get paid to do what you love" (consequence = recognition), which then lead to the value of "making you feel good about yourself/high selfesteem" (self-esteem). Another example started with the attribute of "friends/better to skate together than alone" (interactions), which lead to the consequences of "skate better when you feed off each other's energy" (motivation), "encourage each other with friendly competition" (competition), "cool to watch each other progress and improve/satisfying" (encouragement), which then lead to the value of having a "sense of personal accomplishment/can progress more" (sense of accomplishment).

In Figure 1, the Hierarchical Value Map (HVM), summarizes the means-end relationships among the attributes (white circles), consequences (grey circles), and values (black circles) identified by the entire sample of skateboard park users. The size of each circle is proportional to the number of times the concept identified within the circle was mentioned by the informants. Some of the most predominant attributes include social interactions, skate, skatepark, and terrain. The largest circles that represent consequences included: fun, skill development, and camaraderie and social opportunities. The most mentioned value was fun and enjoyment of life, followed by a sense of accomplishment. The thickness of the lines connecting circles is 
proportional to the number of times concepts linked together. The value level concepts are represented using black circles, labeled in upper-case letters, and are located near the top of the HVM.

Figure 1

Hierarchical Value Map for Utah and California Skateboard Park Participants -

All Respondents $(\mathrm{N}=171)$

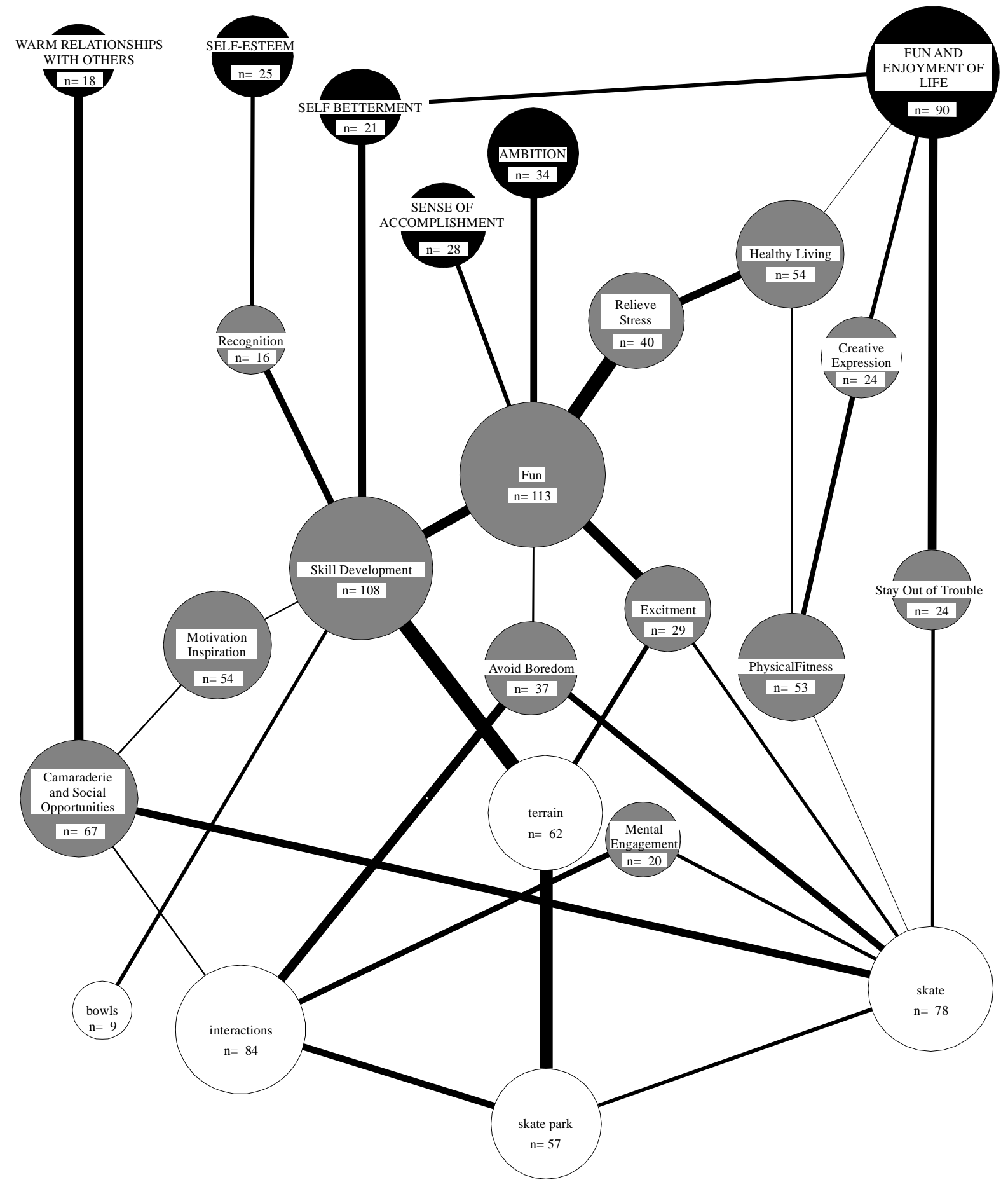


A closer look at Figure 1 reveals a number of noteworthy links between attributes, consequences, and values. For example, skateboarding [skate] led to camaraderie and social opportunities, which then lead to warm relationships with others. The terrain provided opportunities for skill development, which led to fun. Excitement also led to fun. Further, the consequence of fun led to a sense of accomplishment, ambition, and relieving stress. The consequence of skill development led to the value of self-betterment. Another interesting link includes skill development, which led to recognition, which led to self-esteem.

\section{Discussion}

Results suggest that this sample of skateboarders believed that skateboarding at skateboard parks enhanced their lives in a variety of ways such as increasing their fun and enjoyment of life. This is similar to Shannon and Werner's (2008) results, which indicated that "many youth expressed that skateboarding at the skate park was more challenging, exciting, and fun than what they has been able to create for themselves on the streets and in the parking lots, and the opportunities to experience these sensations motivated their attendance at the skate park" (p. 53). Visiting the skateboard park provided them with opportunities for external recognition and a chance to develop self-esteem and self-betterment through skill development in a social setting, which was also similar to Shannon and Werner who stated that "a few youth had their own goals related to their participation and appeared motivated to master particular tricks" ( $p$. 53). These outcomes from the current study are also consistent with those sought through a positive youth development framework (Bocarro et al., 2008; Shannon \& Werner, 2008). In fact, all of the values expressed by the informants are positive in nature and provide some evidence to support the claims of Lemmon and Nowlin (2007) who suggested that skateboard parks provide an important outlet for positive youth development. In general, these results support that notion that providing youth with access to skateboard parks can result in outcomes that enhance their leisure experiences and support positive youth development efforts by providing necessary support for adolescent development (Bocarro et al., 2008; Henderson, Powell, \& Scanlin, 2005).

Camaraderie, social opportunities, skill development, fun, physical fitness, stress relief, and healthy living were among the most salient outcomes identified by respondents. It is important to consider, however, that the results also provide insight into the process or mechanisms through which participants realized these outcomes. A socio-ecological model may provide a useful explanation for the process through which participants achieved the outcomes associated with skateboard park use because it explains human behavior by considering four influential components: intrapersonal psychological factors (personal), interpersonal social factors (social), environmental surroundings (environmental), and policies, that work in concert to dictate an individual's involvement in a physical activity (Kowal \& Fortier, 2007; West \& Shores, 2008). This directs program designers to consider each of these features within their programs and facilities.

Consider the application of present study's results in light of a socio-ecological model. Intrapersonal psychological factors are characteristics of the individual. This is apparent in the participant responses regarding values such as self-esteem, self-improvement, and ambition. Interpersonal social factors are social supports and interactions. This factor appeared in the responses regarding the relevance and importance of social interactions. Environmental surroundings amount to the responses that acknowledged the importance of the terrain. Lastly, policies are the rules that govern the facility, and the respondents acknowledged that they experienced the freedom necessary to pursue their own freely chosen activity. Therefore, in 
response to socio-ecological theory, program designers might consider if their skateboard park, and the policies surrounding the skatepark, create the type of environment that encourages the desired outcome, in this case, physical activity.

Utilizing a socio-ecological model as an explanation for the process through which skateboard park users achieve outcomes is supported further in the results reported by Shannon and Werner (2008). They offered three key outcomes of skateboard park use that they referred to as "enhanced leisure, enhanced skateboarding experiences, and valued space" (p. 46). They reported that access to a new skateboard park afforded their sample increases in physical activity, developmental leisure opportunities, access to preferred leisure activity, and social opportunities. The personal, social, and environmental aspects of the socio-ecological model are clearly present in their findings.

Along with the socio-ecological approach, viewing skateboard park users through a positive youth development framework is recommended. Practitioners are well advised to avoid viewing skateboarders with prejudice, and instead adopt a positive youth development stance by helping skateboard park visitors realize goals such as establishing strong social relationships, having fun, and living healthy lifestyles. It is possible that the skateboarders who frequent a skateboard park are seeking meaningful opportunities to better themselves.

Identifying the physical attributes of the skateboard park, along with the proximal and distal outcomes associated with participation, should inform outcome-based thinking, positive youth development, and comprehensive, intentional, community recreation programs that support positive youth development. Documenting benefits has supported claims that positive outcomes are available to skateboard park visitors. Understanding the values of skateboard park visitors and identifying the attributes that attract them to the skatepark may provide important information for understanding why individuals choose to visit them.

Finally, the present study's results have implications for design that support the claims of Jones and Graves (2000), who suggested that skateboarders use skateboard parks in a different way than tennis players use a tennis court or ball players use a ball field. Design of such traditional athletic facilities is defined by standardized specifications (height of the net, etc.), but skateboard parks cannot be defined in such terms and should, instead, be designed in response to users' goals and specified desirable outcomes. Modern skateboard park designers have focused primarily on the type of features and materials that produce functional and durable skateboard parks. However, well informed parks and recreational professionals think beyond function and durability when they design facilities and programs. They carefully consider targeted outcomes and participant benefits when designing facilities and programs. Although new design trends are emerging that recognize the importance of social interaction and sense of place (Bracal \& Nims, 2007), there is no evidence that skateboard parks have been designed to support the achievement of specified outcomes or benefits. One reason for this may be the historical lack of documented outcomes for skateboard park visitors.

Future research may seek to understand the differences among skateboarders that use skateboard parks and those that do not and to examine the differences between stereotypical views of skateboarders versus the actual attitudes and behaviors of contemporary skateboarders. Another future study could examine skateboard park competitions and outcomes associated with participating in such structured activities. 
This study has identified a number of outcomes that were relevant to a specific sample of skateboard park users. Perhaps a broader approach that focuses on a different method and utilizes a representative sample could add to the present understanding of process and outcomes related to skateboard park use. Finally, socio-ecological theory was suggested as a useful theory to explain the means through which outcomes are realized in the skateboard park setting.

\section{Conclusion}

In conclusion, rather than rely on the negative stereotypes often associated with skateboarding which might suggest that skateboarders are troubled and in need of some intervention, the results indicated that a recommendation to understanding skateboard park use can be through a positive youth development framework. Applying this framework, skateboard parks are one component, among others, utilized by community recreation providers as a means to promote positive outcomes among youth. This is in contrast to viewing the skateboard park as merely a diversion from trouble or as a way to keep young adults occupied. It is not a passive or neutral approach to recreation programming. Instead, it is an active and intentional approach that begins by identifying desired outcomes and then designing programs that achieve those outcomes.

\section{References}

Bocarro, J., Greenwood, P.B., \& Henderson, K.A. (2008). An integrative review of youth development research in selected United States recreation journals. Journal of Park and Recreation Administration, 26(2), 4-27.

Bogdan, R., \& Biklen, S. (1982). Qualitative research for education: An introduction to theory and methods. Boston: Allyn \& Bacon.

Bracal, A.J., \& Nims, J. (2007, October). Creating a "Landscape for skateboarding." National Recreation and Parks Congress. Indianapolis, IN.

Dahlgren, K. (2006). Taking it to the street. Parks and Recreation, 41(8), 39-43.

Frauman, E., \& Cunningham, P.H. (2001). Using a means-end approach to understand the factors that influence greenway use. Journal of Parks and Recreation Administration, 19(3), 93-113.

Gengler, C.E., \& Reynolds, T.J. (1995). LadderMap [Computer Software]. Camden, N]: MeansEnd Software.

Gengler, C.E., Klenosky, D.B., \& Mulvey, M. (1995). Improving the Graphic Representation of Means-End Results, International Journal of Research in Marketing, 12(3), 245-256.

Goldenberg, M., Hill, E., \& Freidt, B. (2008). Why individuals hike the Appalachian Trail: A qualitative approach to benefits [Abstract]. Journal of Experiential Education, 30(3), 277-281. 
Goldenberg, M.A., Klenosky, D.B., O'Leary, J.T., \& Templin, T.J. (2000). A means-end investigation of ropes course experiences. Journal of Leisure Research, 32(2), 208-224.

Goldenberg, M., McAvoy, L., \& Klenosky, D.B. (2005). Outcomes from the components of an Outward Bound experience. Journal of Experiential Education, 28(2), 123-146.

Gutman, J. (1982). A means-end chain model based on consumer categorization processes. Journal of Marketing, 46, 60-72.

Haras, K., Bunting, C.J., \& Witt, P.A. (2005). Linking outcomes with ropes course program design and delivery. Journal of Park and Recreation Administration, 23(2), 36-63.

Henderson, K.A., Powell, G.M., \& Scanlin, M.M. (2005). Observing outcomes in youth development: An analysis of mixed methods. Journal of Park and Recreation Administration, 23(4), 58-77.

Hills, A.P., King, N.A., \& Armstrong, T.P. (2007). The contribution of physical activity and sedentary behaviors to the growth and development of children and adolescents. Sports Med, 276), 533-545.

Howell, O. (2005). The "Creative class" and the gentrifying city: Skateboarding in Philadelphia's love park. Journal of Architectural Education, 32-42.

Hultsman, W. (1996). Benefits of and deterrents to recreation participation: Perspectives of early adolescents. Journal of Applied Recreation Research, 21(3), 213-241.

Jones, S., \& Graves, A. (2000). Power plays in public space: Skateboard parks and battleground, gifts, and expressions of self. Landscape Journal, 19, 136-148.

Klenosky, D., Frauman, E., Norman, W., \& Gengler, C. (1998). Nature-based tourists' use of interpretive services: A means-end investigation. The Journal of Tourism Studies, 9(2), 26-36.

Klenosky, D., Gengler, C., \& Mulvey, M. (1993). Understanding the factors influencing ski destination choice: A means-end analytic approach. Journal of Leisure Research, 25(4), 362-379.

Kowal, J., \& Fortier, M.S. (2007). Physical activity behavior change in middle-aged and older women: The role of barriers and of environmental characteristics. Journal of Behavioral Medicine, 30, 233-242

Lee, E. (2003). The supervision solution: A public-private approach to skatepark management. Parks and Recreation, 38(8), 38-41.

Lemmon H., \& Nowlin, T. (2007). Safe Haven: At-risk youth find solace in skateparks. Parks and Recreation, 42(5), 41-43.

Manyiwa, S., \& Crawford, I. (2002). Determining linkages between consumer choices in a social context and the consumer's values: A means-end approach. Journal of Consumer Behavior, 2(1), 54-70. 
McAvoy, L., Holman, T., Goldenberg, M., \& Klenosky, D. (2006, August). Wilderness and persons with disabilities: Transferring the benefits to everyday life. International Journal of Wilderness, 12(2), 23-31.

Morantz, C., \& Torrey, B. (2004). Clinical briefs. American Family Physician, 69(2), 440-441.

Mulvey, M.S., Olson, J.C., Celsi, R.L., \& Walker, B.A. (1994). Exploring the relationships between means-end knowledge and involvement. Advances in Consumer Research, 21, 1-7.

Ransdell, L.B., Detling, N., Hildebrand, K., Lau, P., Moyer-Mileur, L., \& Shultz. B. (2004). Can physical activity interventions change perceived exercise benefits and barriers? American Journal of Health Studies 19(4), 195-204.

Rankin, M. (1997). We're going to build a what? City-run skateparks are not a recipe for disaster, Parks \& Recreation, 32(7), 54-60.

Reynolds, T.J., \& Gutman, J. (1988). Laddering theory, method, analysis, and interpretation. Journal of Advertising Research, 28(1), 11-31.

Shannon, C.S. \& Werner, T.L. (2008). The opening of a municipal skate park: Exploring the influence on youth skateboarders' experiences.

Walker, B.A., \& Olson, J.C. (1991). Means-end chains: Connecting products with self. Journal of Business Research, 22, 111-118.

West S.T., \& Shores, K.A. (2008). A comparison of four recreation facilitation styles and physical activity outcomes in elementary school children. Journal of Park and Recreation Administration, $26(2), 115-133$.

Young, A. (2004). Being the 'alternative' in an alternative subculture: Gender differences in the experiences of young women and men in skateboarding and snowboarding. Avante, 10(3), 6981.

Note: The authors would like to offer appreciation to the following individuals for assisting with this study: Karen Paisley at the University of Utah and Dan Pronsolino, Barbara Smith, and Breanne Long at Cal Poly State University. This study was also partially funded through a mini-grant provided by the College of Agriculture, Food, and Environmental Sciences at Cal Poly State University, San Luis Obispo.

(C) Copyright of Journal of Youth Development $~$ Bridging Research and Practice. Content may not be copied or emailed to multiple sites or posted to a listserv without copyright holder's express written permission. However, users may print, download or email articles for individual use. 